\title{
The prescription opioid epidemic: an overview for anesthesiologists
}

\section{L'épidémie de prescription d'opioïdes: une vue d'ensemble destinée aux anesthésiologistes}

\author{
Asim Alam, MD • David N. Juurlink, MD, PhD
}

Received: 12 May 2015/Revised: 23 June 2015/Accepted: 15 October 2015/Published online: 27 October 2015

(C) Canadian Anesthesiologists' Society 2015

\begin{abstract}
Purpose The objectives for preparing this article were to review the historical context and epidemiology surrounding the North American prescription opioid crisis, to summarize the evidence regarding the benefits and harms of long-term opioid therapy for non-cancer pain, and to outline ways in which anesthesiologists may help ameliorate the problem.
\end{abstract}

Source We searched PubMed, Google Scholar, and EMBASE ${ }^{T M}$ for relevant articles using various search

This article is accompanied by an editorial. Please see Can J Anesth 2016; 63: this issue.

A. Alam, MD $(\bowtie)$

Department of Anesthesia, Sunnybrook Health Sciences Centre, 2075 Bayview Avenue, Toronto, ON M4N 3M5, Canada

e-mail: asim.alam@sunnybrook.ca

A. Alam, MD

Trauma, Emergency and Critical Care Program, Sunnybrook

Health Sciences Centre, Toronto, ON, Canada

\author{
A. Alam, MD \\ Department of Anesthesia, University of Toronto, Toronto, ON, \\ Canada \\ D. N. Juurlink, MD, PhD \\ Department of Medicine, University of Toronto, Toronto, ON, \\ Canada \\ D. N. Juurlink, MD, PhD \\ Department of Pediatrics, University of Toronto, Toronto, ON, \\ Canada
}

D. N. Juurlink, MD, PhD

Health Policy, Management and Evaluation, University of

Toronto, Toronto, ON, Canada terms, including pain, opioid epidemic, history of opioid use, perioperative care, and addiction. Related citations were further explored and searched depending on the specific subtopic of interest.

Principal findings In the 1980s and early 1990s, opioids were infrequently used for the treatment of chronic pain. Thereafter, however, physicians were gradually inculcated with the message that long-term opioid therapy was a safe and effective treatment option for patients with chronic non-cancer pain. Pharmaceutical companies supported this growing movement and employed aggressive and sometimes misleading marketing strategies for new opioid formulations. As a result, the practice of prescribing opioids flourished in the late 1990s. The surge in prescribing opioids was accompanied by a marked increase in opioid-related morbidity and mortality. This change in practice transpired despite the absence of randomized trials showing clinically significant benefit from the long-term use of opioids. Subsequently, however, a large and growing body of evidence has emerged quantifying the harms associated with long-term opioid therapy. Anesthesiologists widely prescribe opioids for acute and chronic pain; yet, as a group, they may be largely unaware of the current state of this growing epidemic and what role they can play to rectify this problem.

Conclusion Anesthesiologists are well positioned to take a leadership role in the management of postoperative discharge opioid therapy in an effort to curb the overutilization of opioids. Furthermore, anesthesiologists who regularly prescribe opioids for chronic pain patients should appreciate the limited evidence base for this practice and communicate the risks of opioid therapy to their patients. 


\section{Résumé}

Objectif Les objectifs lors de la préparation de cet article étaient de passer en revue le contexte historique et l'épidémiologie entourant la crise de prescription d'opiö̈des nord-américaine, de résumer les données probantes concernant les avantages et les effets nocifs $d u$ traitement opiö̈de à long terme pour les douleurs non cancéreuses, et de proposer différentes pistes aux anesthésiologistes afin qu'ils aident à résoudre le problème.

Source Nous avons effectué des recherches dans les bases de données PubMed, Google Scholar et EMBASE ${ }^{T M}$ afin d'en extraire les articles pertinents à l'aide de différents termes de recherche, notamment douleur, épidémie d'opiö̈des, histoire de l'utilisation d'opiödes, soins périopératoires, et accoutumance (soit les termes anglais pain, opioid epidemic, history of opioid use, perioperative care, et addiction, respectivement). Les citations associées ont été recherchées et explorées selon leur thème secondaire spécifique.

Constatations principales Au cours des années 1980 et au début des années 1990, les opioïdes n'étaient que rarement utilisés pour le traitement de la douleur chronique. Par la suite toutefois, il a été progressivement inculqué aux médecins que le traitement opiö̈de à long terme constituait une option de traitement sécuritaire et efficace pour les patients souffrant de douleur chronique non cancéreuse. Les compagnies pharmaceutiques appuyèrent cet essor et eurent recours à des stratégies commerciales agressives et parfois trompeuses pour promouvoir de nouvelles formulations opiö̈des. Ainsi, la pratique de prescrire des opiö̈des prospéra à la fin des années 1990. Cette montée des prescriptions d'opioïdes s'accompagna d'une augmentation marquée de la morbidité et de la mortalité liées aux opiö̈des. Ce changement de pratique s'étendit malgré l'absence d'études randomisées attestant d'un avantage significatif d'un point de vue clinique quant à l'utilisation à long terme de ces agents. Par la suite toutefois, un corpus grandissant de données probantes émergea, quantifiant les effets nocifs associés à un traitement opiö̈de à long terme. Les anesthésiologistes prescrivent fréquemment des opiö̈des pour le traitement de la douleur aiguë et chronique; pourtant, en tant que collectivité, ils pourraient ne pas être pleinement conscients de l'état actuel de cette crise grandissante et du rôle qu'ils peuvent jouer pour régler ce problème.

Conclusion Les anesthésiologistes occupent une position privilégiée pour assumer un rôle de leadership dans la gestion des traitements opioïdes après le congé postopératoire dans un effort pour ralentir la sur-utilisation des opiö̈des. De plus, les anesthésiologistes qui prescrivent régulièrement des opiö̈des à leurs patients de douleur chronique devraient prendre connaissance des données probantes limitées soutenant cette pratique et expliquer les risques d'un traitement opiö̈de à leurs patients.

The practice of prescribing opioids for chronic non-cancer pain has increased dramatically over the past two decades, particularly in the United States and Canada. ${ }^{1-5}$ This has been accompanied by a marked increase in opioid-related morbidity and mortality. ${ }^{3,6-8}$ In Ontario, the rate of opioidrelated mortality has more than tripled since the early 1990s. ${ }^{1}$ The majority of these deaths occur in young to middle-aged patients, and the resulting burden of premature mortality is significant. ${ }^{1,6}$ Even with recognition of the problem, prescription opioid consumption has continued to increase nationally by almost $70 \%$ since $2008 .^{2}$ Canadians are among the most prolific users of prescription opioids in the world. ${ }^{9}$

In the United States (US), deaths from overdoses of prescription opioids quadrupled from 1999-2010 and now exceed the combined death toll from cocaine and illicit heroin overdoses. ${ }^{3,10}$ Most of these deaths are unintentional, although about one in five are of "undetermined" intent. ${ }^{3}$ The US Department of Health and Human Services (HHS) and the Centers for Disease Control and Prevention (CDC) have declared that overdose deaths involving prescription opioids constitute an epidemic, a decree that has prompted multijurisdictional initiatives. $^{3}$ The same phenomenon-a rise in opioid prescriptions with a corresponding increase in mortality-has been reported in both the United Kingdom (UK) and Australia. ${ }^{4,5}$

While primary care physicians issue most opioid prescriptions, anesthesiologists utilize opioids regularly for anesthesia, acute postoperative pain, and the treatment of chronic pain. Herein, we detail the historical context surrounding the growth of this epidemic and create a framework for future discussion and research in the hope that anesthesiologists can make an important contribution to alleviate this problem. We searched PubMed, Google Scholar, and EMBASE ${ }^{\mathrm{TM}}$ to find relevant articles using various search terms, including pain, opioid epidemic, history of opioid use, perioperative care, and addiction. Related citations were also further explored and searched depending on the specific subtopic of interest. 


\section{Opioids: a brief history}

The use of opioids predates written history. The Sumerians first cultivated the opium poppy around 3400 B.C. ${ }^{11}$ Opium use spread throughout the ancient world to every major civilization in Eurasia where it was used for a variety of medical applications including the treatment of pain. ${ }^{11}$ In 1803, Serturner extracted morphine from opium and named the newly isolated compound after Morpheus, the Greek god of dreams. ${ }^{11,12}$ Thereafter, opium use became widespread throughout the United States; indeed, it is estimated that, during the Civil War, the Union army consumed 2.8 million ounces of opium tincture or powder and about 500,000 opium pills, with a high rate of addiction among its soldiers. ${ }^{13,14}$

In 1874, chemists at Bayer, a German pharmaceutical company, synthesized diacetylmorphine from opium and marketed it under the trade name Heroin ${ }^{\mathrm{TM}}$. They promoted it as more effective and less addictive than morphine $^{11}$ and advocated its use as a non-addictive morphine substitute. In the early 20th century, Heroin ${ }^{\mathrm{TM}}$ was marketed in an oral form as a cough suppressant, ${ }^{6}$ and by the early 1900s, it and other opioids were widely used euphoriants. ${ }^{11}$ It was eventually recognized that heroin was metabolized to a morphine derivative and, in fact, shared all its associated risks. ${ }^{6}$

To curb the socioeconomic problems associated with widespread opioid use, progressive restrictions were implemented on the sale of heroin and other opioids. The Narcotics Tax Act of 1914 made it illegal for physicians to prescribe opioids to treat addiction in the United States, and by 1925, the League of Nations banned the sale of heroin outright. ${ }^{6}$ In the years that followed, pharmaceutical manufacturers synthesized new opioids, including oxycodone and hydromorphone, ${ }^{6}$ and by the 1930s, international regulations were broadened to restrict the use of all opioids.

During the late twentieth century, most physicians viewed opioids as unsuitable for the treatment of chronic pain, reasoning that prescribing them for this purpose would promote pharmacologic tolerance (the progressive need for higher doses to achieve the same effect), dependence, misuse, and addiction. ${ }^{11}$ Nevertheless, during the second half of the twentieth century, physicians became comfortable with the practice of prescribing opioids for acute severe pain and pain due to cancer. ${ }^{6}$ It became apparent that the judicious use of opioids could improve the quality of life for some such patients. ${ }^{6}$ Even so, opioids were rarely prescribed until the 1980s when opinion leaders and professional organizations - many of them with financial ties to opioid manufacturers-began advocating for their broader use in patients with chronic pain. ${ }^{6,15}$

\section{The rise of opioid use for chronic non-cancer pain}

Several publications promoted the notion that opioids could be used safely in patients with chronic pain. In 1977, a cross-sectional study by Medina et al. described 2,369 patients with chronic headaches. Twenty-three of these patients were taking an opioid for at least six months, and only three were considered "abusers". ${ }^{16}$ The article concluded that there is a "danger of dependency and abuse in patients with chronic headaches" taking these medications. Nevertheless, despite its cross-sectional nature and lack of a clear definition of abuse, the study has been cited more than 100 times, ${ }^{\mathrm{A}}$ often as evidence of a low rate of abuse during long-term opioid therapy. ${ }^{17}$

In 1980, Porter and Jick published correspondence in the New England Journal of Medicine describing an examination of the electronic drug records of 39,946 hospital inpatients. ${ }^{18}$ Almost $28 \%$ of the sample had at least one inpatient prescription for an opioid. ${ }^{18}$ Among those patients deemed to have no previous addiction history, only four were deemed to have addiction, and only one had "major addiction". ${ }^{18}$ Although this report consisted of only five sentences and could not ascertain the presence or absence of addiction, it has been cited more than 800 times, ${ }^{\mathrm{A}}$ most often to buttress the notion that addiction is rare in patients receiving opioids.

In 1986, Portenoy and Foley published what would become a seminal article-a retrospective case series of 38 patients who received opioids for chronic pain in the setting of a highly specialized pain clinic. ${ }^{19}$ Most patients were suffering from chronic back, facial, abdominal, extremity, or pelvic pain. Of the patients in this series, half had been treated with opioids for four years or longer. Twelve patients received oxycodone, seven received methadone, and five received levorphanol. The remaining patients received various opioids, including propoxyphene, meperidine, codeine, pentazocine, or some combination of these drugs. ${ }^{19}$ The majority of patients reported adequate or partial analgesia, and only two patients (both with a history of substance abuse) displayed what the investigators characterized as aberrant behaviour. The authors concluded that long-term opioid therapy can be a safe, useful, and more humane alternative to surgery or no treatment among patients with intractable non-cancer pain. ${ }^{19}$

An important and sometimes overlooked aspect of this case series is that the majority of subjects were maintained on less than $20 \mathrm{mg}$ of intramuscular morphine (or equivalent) per day, equivalent to approximately 40- 60 mg of oral morphine. ${ }^{19}$ This contrasts starkly with the high

\footnotetext{
A The number of citations were calculated using Google Scholar (accessed June 19, 2015).
} 
doses commonly employed today among many long-term users. ${ }^{20}$ Another study by Tennant $e t$ al. also described the safety of long-term opioid therapy in patients with chronic non-cancer pain ${ }^{21}$-with similar methodological concerns as above. Collectively, these studies helped reinforce the notion that opioids were safe and effective therapies for chronic pain and that aberrant drug-seeking behaviour was uncommon in this setting. ${ }^{17}$

\section{The surge in prescribing opioids}

In the 1990s, a growing movement developed with the goal of better recognizing and treating all types of pain. An important objective of certain opinion leaders at the time was to destigmatize opioids as a therapeutic option for patients with chronic pain. While a major barrier to the use of opioids for chronic pain was the widely held perception that such treatment carried a high risk of addiction, studies such as those noted above were portrayed as evidence to the contrary.

In the late 1990s, healthcare systems in the United States, including the Department of Veterans Affairs (VA), jointly proclaimed the routine assessment of pain as a necessary intervention. This led to widespread national recognition of pain as a " ${ }^{\text {th }}$ vital sign". ${ }^{22}$ In 2001, the Joint Commission on Accreditation of Healthcare Organizations (JCAHO) established the mandatory early recognition and management of pain as a standard of care. $^{23}$ It is also noteworthy that at least two pharmaceutical companies were involved in funding and providing educational videos and materials for JCAHO regarding the need for better pain management. ${ }^{24}$ As a result, various guidelines were instituted that compelled physicians to prescribe opioids for all types of pain syndromes. Physicians reluctant to prescribe opioids for patients with chronic pain were decried as "opiophobic". ${ }^{15}$ As a result, the sales of opioid analgesics quadrupled in the US during 1999-2010. ${ }^{25}$ Specifically, from 2002-2009, the number of prescriptions for extended-release opioids blossomed from 9.3-22.9 million, a $146 \%$ increase. $^{25}$

In tandem with this growing movement, drug manufacturers began the aggressive promotion of new opioid formulations for the treatment of chronic pain. ${ }^{6,26}$ Legal proceedings have allowed key insights into one major instance of this promotion, namely, the development and marketing of sustained-release oxycodone by Purdue in the US. In 2007, Purdue pleaded guilty to the felony misbranding of OxyContin ${ }^{\mathrm{TM}}{ }^{26}$ They acknowledged capitalizing on the notion that oxycodone was less potent than morphine and suggesting that long-acting oxycodone might be used to "weed out" addicts and drug seekers. ${ }^{27}$ The company's sales representatives were incentivized to increase sales. ${ }^{26,28}$ They issued free samples to pharmacies and targeted high-frequency physician prescribers while reporting a falsely low addiction risk among oxycodone users. ${ }^{26}$ Other opioid manufacturers have also been cited for inappropriate marketing, including Janssen Pharmaceuticals and King Pharmaceuticals. ${ }^{6}$

Less is known about the marketing of opioids in Canada. Nevertheless, in one particularly questionable example, advertisements in Canada for the long-acting formulation of oxycodone included a "pain ladder" styled after the World Health Organization (WHO) ladder developed in 1986 specifically for use in cancer pain. ${ }^{29}$ Purdue's "Modified World Health Organization Pain Ladder" characterized oxycodone as both a strong opioid (alongside morphine) and a weak opioid (alongside codeine) - a misleading and obviously self-contradictory characterization. ${ }^{29}$ The extent to which this influenced Canadian health professionals' perception of opioids, and oxycodone in particular, is unknown.

The aggressive marketing of opioids was not limited to practicing physicians. Pharmaceutical companies directed large amounts of money to support pain curricula for health professional students at several Canadian universities. ${ }^{30}$ In one prominent example, the lecture content and educational materials (including a textbook produced by Purdue and provided free to students) promoted the use of opioids, characterized oxycodone as a weak opioid, and downplayed important adverse events of long-term opioid use. ${ }^{30}$ Moreover, there was a lack of disclosure of conflicts of interest involving several lecturers who were also paid advisors to opioid manufacturers. ${ }^{30}$

The combined effects of misconstrued low-quality evidence, advocacy from prominent healthcare organizations and "thought leaders", and targeted (and often misleading) marketing campaigns by pharmaceutical companies created a milieu in which practitioners became more comfortable with the increasing use of opioids for chronic pain. As a result, prescription opioid therapy increased dramatically, even though the foundations for this practice were weak. The last decade of targeted research has started to unravel the true effects of long-term opioid therapy.

\section{Existing evidence on the benefits of long-term opioid therapy}

Benefits of therapy

Most systematic reviews conclude that there is very little evidence supporting the use of opioids for the long-term treatment of non-cancer pain, which is best characterized as an anecdote-based practice. Recent systematic reviews 
of opioids for chronic back pain, osteoarthritis of the hip, and knee and neuropathic pain have suggested that the potential harm from opioids is likely to exceed their benefits in these settings. ${ }^{31-34}$

It is worth pointing out some of the limitations of the available data. First, most trials are of short duration (typically 12-16 weeks) and use placebo rather than an active therapy as the comparison group. ${ }^{35-37}$ This approach tends to cast the effectiveness of opioids in the best possible light; even then, differences between treatment groups are small and attenuate over time. Second, these trials generally employ "pain scales" as the outcome of interest-an unreliable surrogate for more meaningful outcomes such as quality of life and functional improvement. Third, the patients enrolled in these studies tend to be different from those in real-world practice, in that studies typically exclude patients with significant medical and psychiatric comorbidities, those with pain from multiple sites, women of childbearing age, and patients treated with multiple opioids. Fourth, many studies have high dropout rates and high rates of loss to follow-up, which limits the external validity of the ascertained results. ${ }^{35,38,39}$ It is also important to recognize that many recent trials are conceived, funded, and carried out by the drug companies themselves. In this manner, the company research departments collect and perform analyses on their own data, which, if positive, will have major ramifications for all stakeholders directly involved. As a result, results from these types of research studies are confounded with major conflicts of interest. Despite these limitations, these studies provide sufficient evidence of efficacy, that is, lower short-term pain scores than placebo, to satisfy regulators and obtain market approval. ${ }^{40}$

The recent approval of Zohydro ${ }^{\circledR}$ ER, an extendedrelease analgesic containing hydrocodone made by Zogenix, is a prime example of this phenomenon. This product was approved for "moderate-to-severe chronic pain" in 2014 despite having no features to deter abuse and an outright backlash from lawmakers, industry groups, medical professionals, and US Food and Drug Administration panel advisors alike. Studies for this product utilized an "enriched enrolment" tactic in which individuals who may respond favorably to a therapy can be carefully selected before a clinical trial is initiated. In this manner, the methodology is meant to enhance the overall effect of the drug where only a subset of the population may benefit. As with other opioids, use of Zohydro ER resulted in a marginal reduction in pain scores in a carefully selected group of patients over a 12 -week period vs placebo.
Harms of therapy

A large and growing body of evidence documents that chronic opioid therapy is associated with multiple specific adverse effects relative to other analgesics, including adverse cardiovascular events, fractures, and other events requiring hospitalization, especially among elders treated for pain. ${ }^{8,34,41-44}$ As a result, a recent clinical review recommends initiating long-term opioid therapy only when patients have moderate to severe pain leading to substantial impairment in daily living and when all other treatment modalities have failed. ${ }^{45}$ This is not a recommendation founded on demonstrable evidence of benefits exceeding harms. Moreover, these guidelines are often not observed in clinical practice, as many practitioners continue to initiate opioids as a first-line therapy in the treatment of various chronic pain syndromes.

The effectiveness of long-term usage of opioids in improving other key patient outcomes has also been questioned. A cross-sectional study based on the 2000 Danish Health and Morbidity Survey evaluated the longterm effects of opioids on pain relief, quality of life, and functional capacity in long-term/chronic non-cancer pain. ${ }^{46}$ As part of a nationally representative sample, 10,066 subjects completed a self-administered questionnaire. Participants reporting pain were divided into opioid and non-opioid users and compared in terms of pain relief, quality of life, and functional capacity. Although the severity and duration of baseline pain problems were not reported in this study, opioid usage was significantly associated with moderate/severe or very severe pain, poor health, reduced employment, greater use of the healthcare system, and a reduction in quality of life. ${ }^{46} \mathrm{~A}$ recent systematic review for a National Institutes of Health Pathways to Prevention Workshop concluded that no longterm ( $>$ one year) opioid therapy was evaluated for outcomes related to pain, function, and quality of life. ${ }^{34}$ Overall, there is a paucity of evidence supporting the benefits of long-term opioid therapy for chronic non-cancer pain and virtually no evidence documenting that the benefits exceed the risks.

There is also a substantial risk for problematic drug use among long-term opioid users, although capturing precise rates has been fraught with difficulty due to the imprecise terminology used to define outcome variables in previous studies and reviews. Nevertheless, the journal Pain published a recent systematic review with explicitly defined terms which led to a better estimate of the current problem. ${ }^{47}$ The report suggests that, although rates of problematic usage range from $1-81 \%$ across 
various studies, rates of misuse averaged $21-29 \%$ while rates of addiction averaged $8-12 \%$. Therefore, in addition to potentially being of minimal therapeutic benefit to patients, misuse and addiction remain common among long-term chronic opioid users. ${ }^{47}$

\section{Implications for anesthesiologists}

Anesthesiologists often confront chronic pain patients after opioid doses have been escalated by other practitioners. This escalation is often associated with little or no further benefit to the patient. As a result, patients are referred to a chronic pain specialist who is often faced with not only the failure of high-dose opioids but also the problems of pharmacologic tolerance, opioid dependence, and in some cases, opioid-induced hyperalgesia. ${ }^{48,49}$ The consensus of most specialists is that opioids may have a place in the management of chronic non-cancer pain as one element of multimodal therapy with regular monitoring in very carefully selected patients. ${ }^{50}$ The risks and benefits of this strategy must be weighed on a case-by-case basis. ${ }^{50}$

Some patients who develop postoperative pain go on to suffer from chronic pain. Most anesthesiologists recognize that certain surgeries carry higher risks of chronic pain than others. ${ }^{51}$ There is a growing view that preemptive analgesia in specific surgeries may be helpful in reducing the incidence of chronic post-surgical pain, but there are few well-designed studies supporting this opinion. ${ }^{52}$ Active research is underway to ascertain whether prescribing practices in the perioperative period can influence the longterm utilization of opioids in the first place.

One major study among almost 400,000 opioid-naive Ontarians undergoing short-stay low-risk surgery explored this possibility. ${ }^{53}$ Among these patients, opioids were newly prescribed to 27,636 patients $(7.1 \%)$ within seven days of hospital discharge after low-risk surgery; overall, $10.3 \%$ of these patients continued opioids one year from surgery. ${ }^{53}$ During this time, an increase in the use of oxycodone was found (from 5.4\% within seven days to $15.9 \%$ at one year). ${ }^{53}$ In the primary analysis, patients receiving an opioid prescription within seven days of surgery were $44 \%$ more likely to become long-term opioid users within one year compared with those who received no such prescription (adjusted odds ratio, 1.44; 95\% confidence interval, 1.39 to 1.50$).{ }^{53}$ Curiously, an even higher risk was found for patients who commenced NSAIDS in the perioperative period. ${ }^{53}$ A similar study among emergency patients has corroborated these findings, suggesting opioid naive patients who received opioids for acute pain in the emergency department were at increased risk for additional opioid use at one year. ${ }^{54}$ Of course, these above observational studies are hypothesis-generating and further research is needed to delineate causation.

In recent years, there has been an increased demand for complex surgical procedures to become more ambulatory in nature. ${ }^{55}$ Patients are being discharged from hospital earlier with the plan that their acute postoperative pain can be managed with larger prescriptions of self-administered opioids. ${ }^{55}$ There is evidence that certain patients receive more opioids than needed in the postoperative period. ${ }^{55}$ As a result, unused opioids may become available for later use by the patient or may be diverted to others. ${ }^{55}$

Anesthesiologists are ideally placed to address problems associated with inappropriate postoperative opioid prescriptions. Acute pain services, which are generally directed by anesthesiologists, could extend the reach of their clinical service to being responsible for managing discharge pain prescriptions. This would facilitate a more complete continuum of acute pain care in the perioperative period and allow anesthesiologists to exercise leadership by providing education on the proper utilization and prescription of opioids in the immediate post-discharge period. More importantly, anesthesiologists can ensure that limited yet adequate opioid prescriptions are given to patients, thereby facilitating an efficient discharge process. Although limited data exist on the efficacy of this methodology, in our view, it may help curtail the negative consequences of inappropriate postoperative opioid prescriptions.

\section{Future directions}

The treatment of patients with chronic pain is a vexing problem with no easy solutions. Treatment planning will require a clear understanding of the patient's treatment goals and expectations, comorbidities, and physiological status. It is essential to have a combination of pharmacologic, non-pharmacologic, and rehabilitative approaches in addition to a strong therapeutic alliance between the patient and physician. This multimodal therapeutic plan will require continual readjustment as therapy progresses. Prescribing opioids to maximize benefit while minimizing harm requires an accurate appreciation of the risks of therapy. ${ }^{17}$ As a result, tools and strategies must be developed to help curb the inappropriate prescribing of opioid analgesics, which appears to be driving the opioid epidemic. ${ }^{3}$

Opioid prescription courses offered through regulatory colleges and/or continuing medical education institutions have been proven to help reduce absolute quantities of opioids prescribed, particularly among physicians who prescribe large quantities of opioids. ${ }^{56}$ Allowing an acute 
pain service anesthesiologist to have a more systemic and algorithmic role in the prescription of post-discharge opioid analgesics in the perioperative period could help curb the inappropriate prescription of opioids in this setting. Regardless, additional research is needed in this area of quality improvement. All clinicians, including anesthesiologists, should discard the notion that addiction and dependence is a rare consequence of long-term opioid therapy. It is of utmost importance to exercise caution and vigilance when prescribing opioids in the post-discharge period, as even brief exposure may be the gateway for further inappropriate and chronic use. ${ }^{17,53}$ Communication with patients regarding the real potential risks and benefits of these drugs is paramount before initiating these medications in both the acute and chronic pain settings.

Sources of funding There were no specific sources of funding required for this project.

Conflicts of interest None declared.

\section{References}

1. Gomes T, Mamdani MM, Dhalla IA, Cornish S, Paterson JM, Juurlink $D N$. The burden of premature opioid-related mortality. Addiction 2014; 109: 1482-8.

2. Fischer B, Gooch J, Goldman B, Kurdyak P, Rehm J. Nonmedical prescription opioid use, prescription opioid-related harms and public health in Canada: an update 5 years later. Can J Public Health 2014; 105: e146-9.

3. Volkow ND, Frieden TR, Hyde PS, Cha SS. Medication-assisted therapies - tackling the opioid-overdose epidemic. N Engl J Med 2014; 370: 2063-6.

4. Rintoul AC, Dobbin MD, Drummer OH, Ozanne-Smith J. Increasing deaths involving oxycodone, Victoria, Australia, 2000-09. Inj Prev 2011; 17: 254-9.

5. Handley SA, Flanagan RJ. Drugs and other chemicals involved in fatal poisoning in England and Wales during 2000-2011. Clin Toxicol 2014; 52: 1-12.

6. Dhalla IA, Persaud N, Juurlink DN. Facing up to the prescription opioid crisis. BMJ 2011; 343: d5142.

7. Johnson EM, Lanier WA, Merrill RM, et al. Unintentional prescription opioid-related overdose deaths: description of decedents by next of kin or best contact, Utah, 2008-2009. J Gen Intern Med 2013; 28: 522-9.

8. Gomes T, Redelmeier DA, Juurlink DN, Dhalla IA, Camacho X, Mamdani MM. Opioid dose and risk of road trauma in Canada: a population-based study. JAMA Intern Med 2013; 173: 196-201.

9. Webster $P C$. Medically induced opioid addiction reaching alarming levels. CMAJ 2012; 184: 285-6.

10. Dart RC, Surratt HL, Cicero TJ, et al. Trends in opioid analgesic abuse and mortality in the United States. N Engl J Med 2015; 372: $241-8$.

11. Rosenblum A, Marsch LA, Joseph H, Portenoy RK. Opioids and the treatment of chronic pain: controversies, current status, and future directions. Exp Clin Psychopharmacol 2008; 16: 405-16.

12. Brownstein MJ. A brief history of opiates, opioid peptides, and opioid receptors. P Natl Acad Sci USA 1993; 90: 5391-3.
13. Schiff PL. Opium and its alkaloids. Am J Pharm Educ 2002; 66: 186-94.

14. Quinones MA. Drug abuse during the Civil War (1861-1865). Int J Addict 1975; 10: 1007-20.

15. Andersen S, Leikersfeldt G. Management of chronic nonmalignant pain. Br J Clin Pract 1996; 50: 324-30.

16. Medina JL, Diamond $S$. Drug dependency in patients with chronic headaches. Headache 1977; 17: 12-4.

17. Juurlink DN, Dhalla IA. Dependence and addiction during chronic opioid therapy. J Med Toxicol 2012; 8: 393-9.

18. Porter J, Jick $H$. Addiction rare in patients treated with narcotics. N Engl J Med 1980; 302: 123.

19. Portenoy RK, Foley KM. Chronic use of opioid analgesics in nonmalignant pain: report of 38 cases. Pain 1986; 25: 171-86.

20. Gomes T, Juurlink DN, Dhalla IA, Mailis-Gagnon A, Paterson $J M$, Mamdani MM. Trends in opioid use and dosing among socioeconomically disadvantaged patients. Open Med 2011; 5: e13-22.

21. Tennant F Jr, Robinson D, Sagherian A, Seecof R. Chronic opioid treatment of intractable, non-malignant pain. NIDA Res Monogr 1988; 81: 174-80.

22. Lorenz KA, Sherbourne CD, Shugarman LR, et al. How reliable is pain as the fifth vital sign? J Am Board Fam Med 2009; 22: 2918.

23. Hanks $S$. The law of unintended consequences: when pain management leads to medication errors. P T 2008; 33: 420-5.

24. Government Accounting Office. OxyContin abuse and diversion and efforts to address the problem: highlights of a government report. J Pain Palliat Care Pharmacother 2004; 18: 109-13.

25. Manchikanti L, Helm $S 2^{\text {nd }}$, Fellows B, et al. Opioid epidemic in the United States. Pain Physician 2012; 15: ES9-38.

26. Poitras G. OxyContin, prescription opioid abuse and economic medicalization. Medicolegal and Bioethics 2012; 2: 31-43.

27. United States District Court, Western District of Virginia. United States of America v The Purdue Frederick Company Inc., et al. Opinion and order. Case No. 1:07CR00029. Available from URL: http://www.vawd.uscourts.gov/OPINIONS/JONES/107CR00029. PDF (accessed June 2015).

28. Van Zee A. The promotion and marketing of OxyContin: commercial triumph, public health tragedy. Am J Public Health 2009; 99: 221-7.

29. Jovey RD. Managing Pain: The Canadian Healthcare Professional's Reference. Sittsville: Purdue Pharma; 2008.

30. Persaud N. Questionable content of an industry-supported medical school lecture series: a case study. J Med Ethics 2014; 40: 414-8.

31. Chaparro LE, Furlan AD, Deshpande A, Mailis-Gagnon A, Atlas $S$, Turk DC. Opioids compared to placebo or other treatments for chronic low-back pain. Cochrane Database Syst Rev 2013; 8: CD004959.

32. Chaparro LE, Furlan AD, Deshpande A, Mailis-Gagnon A, Atlas $S$, Turk $D C$. Opioids compared with placebo or other treatments for chronic low back pain: an update of the Cochrane Review. Spine (Phila Pa 1976) 2014; 39: 556-63.

33. Nuesch E, Rutjes AW, Husni E, Welch V, Juni P. Oral or transdermal opioids for osteoarthritis of the knee or hip. Cochrane Database Syst Rev 2009; 4: CD003115.

34. Chou R, Turner JA, Devine EB, et al. The effectiveness and risks of long-term opioid therapy for chronic pain: a systematic review for a National Institutes of Health Pathways to Prevention Workshop. Ann Intern Med 2015; 162: 276-86.

35. Furlan AD, Sandoval JA, Mailis-Gagnon A, Tunks E. Opioids for chronic noncancer pain: a meta-analysis of effectiveness and side effects. CMAJ 2006; 174: 1589-94.

36. Manchikanti L, Ailinani $H$, Koyyalagunta D, et al. A systematic review of randomized trials of long-term opioid management for chronic non-cancer pain. Pain Physician 2011; 14: 91-121. 
37. Kissin I. Long-term opioid treatment of chronic nonmalignant pain: unproven efficacy and neglected safety? J Pain Res 2013; 6: 513-29.

38. Kalso E, Edwards JE, Moore RA, McQuay HJ. Opioids in chronic non-cancer pain: systematic review of efficacy and safety. Pain 2004; 112: 372-80.

39. Noble M, Treadwell JR, Tregear SJ, et al. Long-term opioid management for chronic noncancer pain. Cochrane Database Syst Rev 2010; 1: CD006605.

40. Chou R, Ballantyne JC, Fanciullo GJ, Fine PG, Miaskowski C. Research gaps on use of opioids for chronic noncancer pain: findings from a review of the evidence for an American Pain Society and American Academy of Pain Medicine clinical practice guideline. J Pain 2009; 10: 147-59.

41. Solomon DH, Rassen JA, Glynn RJ, Lee J, Levin R, Schneeweiss $S$. The comparative safety of analgesics in older adults with arthritis. Arch Intern Med 2010; 170: 1968-78.

42. Miller M, Sturmer T, Azrael D, Levin R, Solomon DH. Opioid analgesics and the risk of fractures in older adults with arthritis. $J$ Am Geriatr Soc 2011; 59: 430-8.

43. Jena AB, Goldman D, Weaver L, Karaca-Mandic P. Opioid prescribing by multiple providers in Medicare: retrospective observational study of insurance claims. BMJ 2014; 348: g1393.

44. Saunders KW, Dunn KM, Merrill JO, et al. Relationship of opioid use and dosage levels to fractures in older chronic pain patients. J Gen Intern Med 2010; 25: 310-5.

45. Makris UE, Abrams RC, Gurland B, Reid MC. Management of persistent pain in the older patient: a clinical review. JAMA 2014; 312: 825-36.

46. Eriksen J, Sjogren P, Bruera E, Ekholm O, Rasmussen NK. Critical issues on opioids in chronic non-cancer pain: an epidemiological study. Pain 2006; 125: 172-9.
47. Vowles KE, McEntee ML, Julnes PS, Frohe T, Ney JP, van der Goes DN. Rates of opioid misuse, abuse, and addiction in chronic pain: a systematic review and data synthesis. Pain 2015; 156: 569-76.

48. Deyo RA, Von Korff M, Duhrkoop D. Opioids for low back pain. BMJ 2015; 350: g6380.

49. Bannister $K$. Opioid-induced hyperalgesia: where are we now? Curr Opin Support Palliat Care 2015; 9: 116-21.

50. Gupta S, Atcheson R. Opioid and chronic non-cancer pain. J Anaesthesiol Clin Pharmacol 2013; 29: 6-12.

51. Clarke H, Soneji N, Ko DT, Yun L, Wijeysundera DN. Rates and risk factors for prolonged opioid use after major surgery: population based cohort study. BMJ 2014; 348: g1251.

52. Vadivelu N, Mitra S, Schermer E, Kodumudi V, Kaye AD, Urman $R D$. Preventive analgesia for postoperative pain control: a broader concept. Local Reg Anesth 2014; 7: 17-22.

53. Alam A, Gomes T, Zheng H, Mamdani MM, Juurlink DN, Bell $C M$. Long-term analgesic use after low-risk surgery: a retrospective cohort study. Arch Intern Med 2012; 172: 425-30.

54. Hoppe JA, Kim H, Heard K. Association of emergency department opioid initiation with recurrent opioid use. Ann Emerg Med 2015; 65(493-99): e4.

55. MacIntyre PE, Huxtable CA, Flint SL, Dobbin MD. Costs and consequences: a review of discharge opioid prescribing for ongoing management of acute pain. Anaesth Intensive Care 2014; 42: $558-74$.

56. Kahan M, Gomes T, Juurlink DN, et al. Effect of a course-based intervention and effect of medical regulation on physicians' opioid prescribing. Can Fam Physician 2013; 59: e231-9. 